\begin{tabular}{|c|c|c|c|}
\hline DE & \multirow{3}{*}{$\begin{array}{l}\text { DE GRUYTER } \\
\text { OPEN }\end{array}$} & $\begin{array}{l}\text { HUNGARIAN JOURNAL OF } \\
\text { INDUSTRY AND CHEMISTRY }\end{array}$ & \multirow[t]{3}{*}{$\begin{array}{l}\text { HUUNGARLAN JOURNAAL OI } \\
\text { INIDUSTIRY ANID CHIEMISTIRYY }\end{array}$} \\
\hline & & Vol. 43(1) pp. 39-43 (2015) & \\
\hline & & $\begin{array}{l}\text { hjic.mk.uni-pannon.hu } \\
\text { DOI: } 10.1515 / \text { hjic-2015-0007 }\end{array}$ & \\
\hline
\end{tabular}

\title{
GROUNDWATER REMEDIATION USING BIOLOGICAL AND PHOTOCATALYTIC METHODS
}

\author{
SÁNDOR GUBA, ${ }^{1 *}$ VIOLA SOMOGYI, ${ }^{2}$ AND ERZSÉBET SZABÓNÉ BÁRdOS ${ }^{3}$ \\ ${ }^{1}$ Institute of Physics and Mechatronics, University of Pannonia, Egyetem u. 10, Veszprém, 8200, \\ HUNGARY \\ 2 Institute of Environmental Engineering, University of Pannonia, Egyetem u. 10, Veszprém, 8200, \\ HUNGARY \\ ${ }^{3}$ Department of General and Inorganic Chemistry, University of Pannonia, Egyetem u. 10, \\ Veszprém, 8200, HUNGARY
}

\begin{abstract}
The degradability of two commercially available pesticides was studied using heterogeneous photocatalytic and activated sludge treatment methods. The first pesticide contained $5 \%$ quizalofop-P-ethyl as an active ingredient and petroleum naphtha as a solvent, the latter causing difficulties both in photocatalytic and biological treatment methods. The active ingredient of the second compound was acetamiprid. The photocatalysis proved to be effective both under laboratory conditions (using UV light) and when exposed to sunlight, but the pesticides remained stable during the employed biological treatment. Preliminary information on its behaviour in soil was obtained from transport modelling.
\end{abstract}

Keywords: heterogeneous photocatalysis, groundwater remediation, quizalofop-P-ethyl, acetamiprid, biological treatment

\section{Introduction}

The drinking water supply of Hungary largely relies on underground water resources. The water quality has been endangered by both industry over the last century and the still significant pesticide-intensive agriculture. Excessive amounts of pesticides contaminating soil may be fully or partially degraded by natural chemical and biochemical reactions. The latter may lead to bioaccumulation. The transport into groundwater and/or surface water bodies is affected by several factors, such as precipitation, evapotranspiration, infiltration, and runoff besides the physicochemical characteristics of soil and the attributes of the substance.

The application of pesticides is an inefficient procedure, since only a small amount is utilised for the desired purpose. Most of the compound is released unused into the soil and if it degrades partially or at a slower pace, the pesticide might accumulate and enter the food chain. In order to avoid the release of pesticides that are persistent and harmful to the environment and humans, it is necessary to have licencing procedures and strict controls on the use of such materials [1]. In Hungary, authorisation is regulated by the Decree $89 / 2004$ of the Ministry of Agriculture and Rural Development in agreement with the Council Directive 91/414/EEC [2].

*Correspondence: gubas@almos.uni-pannon.hu
A common method to treat contaminated aquifers is groundwater pump-and-treat technology [3], where extraction wells are used to remove the contaminated water that is treated with adequate techniques after which it is re-injected into the aquifer or released into a surface water body. The treatment method is dependent on the degradability and toxicity of the pollutant.

Bioremediation cannot be used in cases when the compound is not biodegradable or even toxic to microorganisms. Oxidative methods, such as heterogeneous photocatalysis may be adequate in such cases [4]. In this process, the radicals formed due to the photogenerated charge-carriers on the surface of the semiconductor. They react with the pollutant molecule initiating its degradation. The catalyst is often reusable and recycled. The semiconductor catalyst has to be chemically and biologically inert, but photocatalytically active. It should be easily produced and economical. Since $\mathrm{TiO}_{2}$ fits these requirements, it is the best among the semiconductors for extensive use [5]. Research over the past years has proved that on a laboratory scale different organic compounds (aliphatic and aromatic hydrocarbons [6], alcohols and organic acids [7], phenols [8] and chlorinated compounds [9]) could be effectively degraded to inorganic end products using heterogeneous photocatalysis [10].

The aim of this paper is to report on the degradability of organic contaminants in the soil and groundwater with biological and photocatalytic methods using model compounds. Their behaviour in the soil 

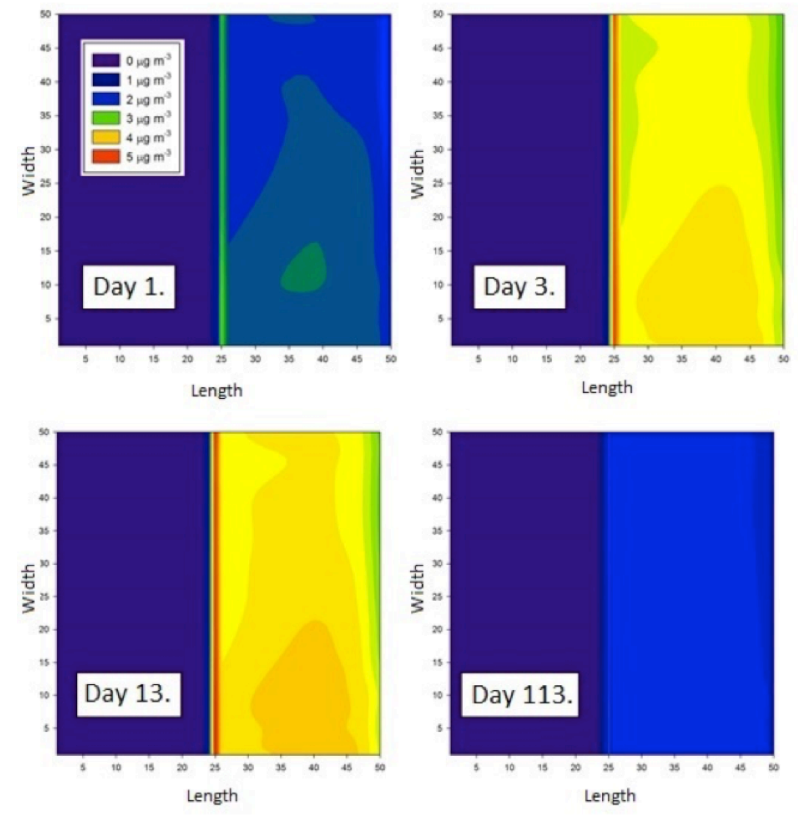

Figure 1. The concentration of quizalofop-P-ethyl in the second layer in the case of normal use (a unit equals $2 \mathrm{~m}$ ).

was determined by hydraulic and transport models. The model compounds were a herbicide (Leopard 5 EC) and an insecticide (Mospilan 20 SG). Both fall into category III meaning that they are available without a special licence. Their metabolites remain stable in soil for a long period.

\section{Methods and Materials}

The substance with the brand name Leopard 5 EC contains 5\% quizalofop-P-ethyl (Scheme 1A) as an active ingredient, $77-83 \%$ petroleum naphtha as a solvent and other emulsifying excipients. The active substance is especially dangerous to mammals, aquatic organisms, and birds and moderately toxic to bees. It is insoluble in water; it emulsifies due to the additives. Its metabolites are more soluble in water, but do not hydrolyse. Their half-lives are between 35 and 39 days.

The active ingredient of the insecticide called Mospilan 20 SG is 20\% acetamiprid (Scheme 1B), which is highly toxic to mammals and birds and moderately toxic to aquatic organisms. The substance is very soluble in water, hence its high mobility upon infiltration. Its metabolite is not easily degraded under natural conditions in soil and water (its half-life is 133 days), and it is moderately toxic to aquatic life.

Heterogeneous photocatalytic irradiation experiments were performed in a photoreactor with an effective volume of $2.5 \mathrm{dm}^{3}$. Internal recirculation was provided in the tube reactor. $\mathrm{TiO}_{2}$ was used as a catalyst with a concentration of $1 \mathrm{~g} \mathrm{dm}^{-3}$, while the air flow was $40 \mathrm{dm}^{3} \mathrm{~h}^{-1}$. The radiation source placed in the axis of the reactor was a $40 \mathrm{~W}$ fluorescent lamp specially manufactured for such purposes. The vast majority of light emitted is of a longer wavelength than $300 \mathrm{~nm}$.<smiles>CCOC(=O)C(C)Oc1ccc(Oc2cnc3cc(Cl)ccc3n2)cc1</smiles><smiles>CC(=NC#N)N(C)Cc1ccc(Cl)nc1</smiles>

Scheme 1. Schematic structures of pesticides studied in this work (A: quizalofop-p-ethyl, Ref: DPX 79376, http://sitem.herts.ac.uk/aeru/ppdb/en/Reports/583.htm (11.05.2015); B: acetamiprid, Ref: NI 35, http://sitem.herts.ac.uk/aeru/ppdb/en/Reports/11 htm (11.05.2015)).

Biological treatment was carried out in an activated sludge, aerated sequenced batch reactor. An operating cycle lasted for a day. The effective volume of the reactor was $5 \mathrm{dm}^{3}$ and the sludge concentration was kept at $4 \mathrm{~g} \mathrm{dm}^{-3}$. The rate of aeration was kept constant throughout the process. A non-adapted municipal sludge was used for the experiments.

Modelling was carried out using Processing MODFLOW for Windows (PMWIN) 5.3. This version is freely available, while later versions can be obtained commercially. The test area was chosen to be the size of 1 acre divided vertically into three homogenous layers with average Hungarian properties. Simulations were run for 1-3-13-113 day intervals. The environmental factors taken into consideration were the following: groundwater flow and porosity, infiltration due to precipitation $\left(1.9 \mathrm{~mm} \mathrm{day}^{-1}\right)$, and evapotranspiration $\left(1.2 \mathrm{~m} \mathrm{day}^{-1}\right)$ [11]. The hydraulic conductivity was $129.6 \mathrm{~mm} \mathrm{day}^{-1}$ for all three layers [12].

\section{Results and Analysis}

\subsection{Leopard 5 EC}

The degradability of the substance with heterogeneous photocatalysis was examined under laboratory (UVlight) and natural (sunlight) conditions. The initial concentration of the active ingredient was $3.26 \mathrm{~g} \mathrm{dm}^{-3}$. The solution was heavily foaming whilst the reactor was being filled. During irradiation, the majority of the catalyst deposited onto the bottom or adhered to the walls of the reactor and buffer tank after an hour despite being stirred. The organic carbon content of the mixture did not change, which indicates that no degradation took place.

In the biological treatment, the components of the solution entering the cycle were: $100 \mathrm{~cm}^{3}$ of herbicide with a concentration of $3.26 \mathrm{~g} \mathrm{dm}^{-3}, 100 \mathrm{~cm}^{3}$ of acetic acid $\left(0.93 \mathrm{~g} \mathrm{dm}^{-3}\right), 10 \mathrm{~cm}^{3}$ of ammonium chloride solution $\left(30 \mathrm{mg} \mathrm{N} \mathrm{dm}^{-3}\right)$, and $10 \mathrm{~cm}^{3}$ of sodium phosphate $\left(30 \mathrm{mg} \mathrm{P} \mathrm{dm}^{-3}\right)$. After turning the stirrer and aeration on the liquid started to foam heavily and smelled strongly of oil. At the end of the cycle in the settling phase the effluent was turbid. Colloids and a part of the activated sludge deposited on the wall of the 

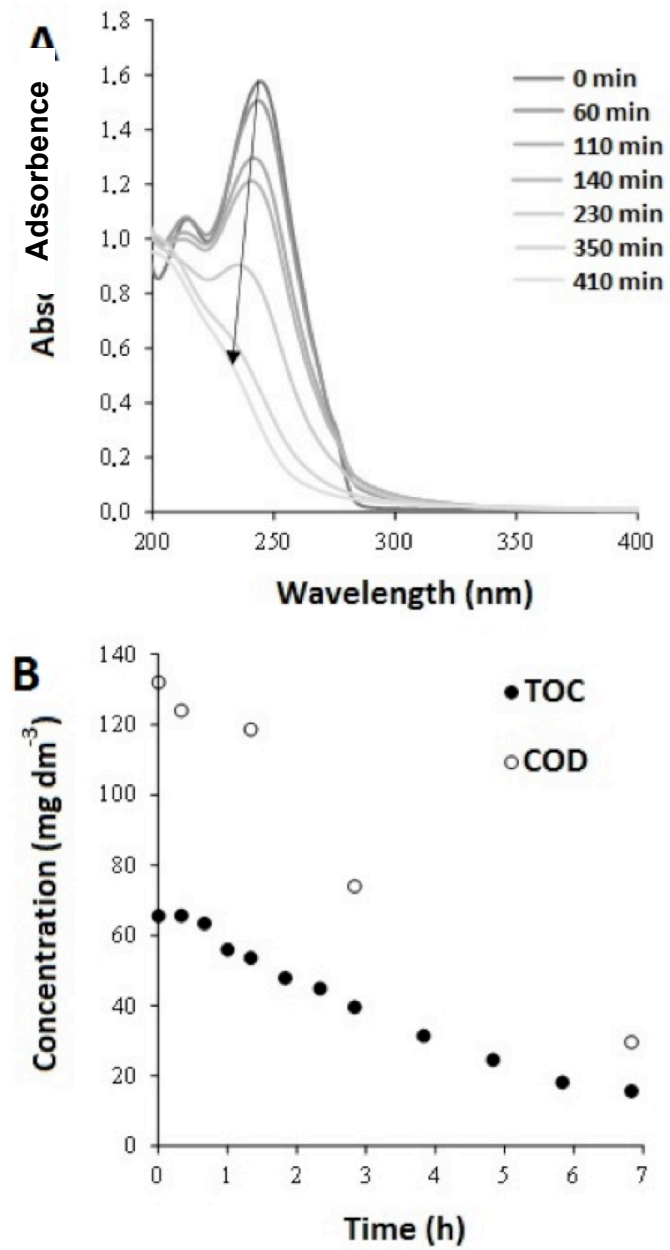

Figure 2. Spectra of Mospilan suspension treated with catalyst (optical path length: $0.5 \mathrm{~cm})(\mathrm{A})$; chemical oxygen demand and total organic carbon concentrations as function of time (B).

sequenced batch reactor and surface of the sensors and dried there. The following cycle ended with the same results. The treatment using activated sludge turned out to be ineffective due to the experienced foaming and cumulated active ingredient. Inspections revealed that the degradation of the solvent did not start either.

The transport models created with the software (Fig.1) showed that pesticide under normal conditions of use did not threaten drinking water resources and due to hydrolysis the concentration decreased by half in the second stratum over 113 days. In the case of accidental spillages (the same amount of compound was hypothetically released over a $2 \mathrm{~m}^{2}$ area) the effect was significant, the concentration was a thousand times grater compared to normal use scenarios.

\subsection{Mospilan $20 \mathrm{SG}$}

In the experiments the concentration of Mospilan used was $170 \mathrm{mg} \mathrm{dm}^{-3}$ in agreement with the suggested concentration of application. A 20\% active ingredient content was achieved by an acetamiprid solution with a concentration of $34 \mathrm{mg} \mathrm{dm}^{-3}$. Photodegradation was monitored by recording the UV-VIS spectra of the mixture and measuring the organic carbon content (TOC).
The solution was first irradiated with UV-light without a catalyst under atmospheric pressure for three hours. During this time neither the TOC concentration nor the $\mathrm{pH}$ of the mixture changed; the variation of the results stayed within the measurement error, which suggested that the insecticide was not degradable by UV-light in itself.

The second experiment was carried out with $\mathrm{TiO}_{2}$ as a catalyst and the process was not stopped for seven hours. During this time the rate of light absorption between 200 and $300 \mathrm{~nm}$ gradually decreased and the maximum of the band shifted from $245 \mathrm{~nm}$ to $230 \mathrm{~nm}$ (Fig.2). These spectral changes indicate clearly that the compound degraded in the heterogeneous photocatalytic experiments.

The suspension was circulated in the reactor for 20 minutes before irradiation. From changes in TOC concentration, it can be concluded that during this period a proportion of the organic material had adsorbed onto the catalyst particles. The rate of adsorption in terms of TOC was $10 \%$. By the end of the process, the TOC concentration of the suspension reduced by $76 \%$ while the COD amount became $78 \%$ less. According to the data, the initial rate of decay was calculated to be $13.59 \mathrm{mg} \mathrm{dm}^{-3} \mathrm{~h}^{-1}$ based on the curve fitted to the TOC.

A major advantage of the heterogeneous photocatalyst is that the reaction may be carried out with solar radiation; thus, costs and also environmentally harmful emissions can be reduced. Photons are on the one hand 'pure' reagents and on the other hand 'pure' energy. The changes in the spectrum, such as the decrease in absorbence and the shift in location of band peaks were the same under laboratory conditions, while the reaction rate was lower. The initial rate of decay due to solar radiation was $6.07 \mathrm{mg} \mathrm{dm}^{-3}$ $\mathrm{h}^{-1}$. During measurements the UV-B radiation was "strong" (UV index 6.5, Hungarian Meteorological Service).

The results show that the heterogeneous photocatalytic degradation of the insecticide may be efficiently achieved by using sunlight. This can be utilised when disposing of different chemical residues. The organic contaminants may be mineralised using solar radiation on site in a carefully designed "reactor".

The biodegradability of the pesticide was studied with a prepared solution based on an average concentration of application. In the first case, an additional substrate (acetic acid) was added to the sequenced batch reactor while in the second case only the insecticide was supposed to serve as a substrate. Based on the results (Fig.3), it can be stated that the biodegradation of Mospilan cannot be achieved with municipal activated sludge under the employed conditions.

The results of the transport model (Fig.4) show that acetamiprid acts in a similar way to quizalofop-P-ethyl. Since it does not hydrolyse the active ingredient, it would remain for longer in soil and accumulation might appear therefore the compound may more easily enter the food chain. In the case of accidental spillages of the substance over a small area, the effect would be more significant just as was the case with quizalofop-P-ethyl. 


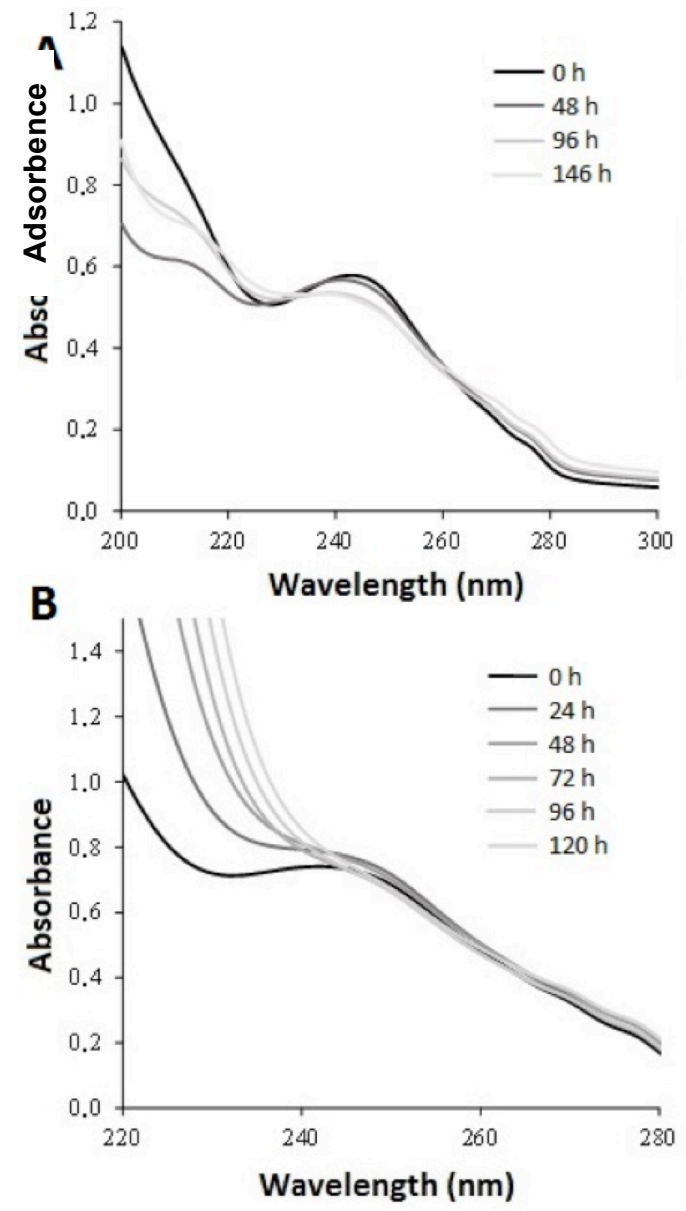

Figure 3. Changes in absorbence spectra during biological treatment with (A) and without additional substrate (B) (optical length: $0.5 \mathrm{~cm}$ ).

The concentration in soil would be a thousand fold greater. Besides it would not decrease significantly over time, since the compound is stable in aqueous media.

\section{Conclusion}

The studied Leopard 5 EC and Mospilan 20 SG pesticides are available to purchase without any permit, although they are toxic to different extents to mammals, birds and aquatic organisms. Their improper application might cause serious environmental damage. The degradability of the two substances was studied by means of heterogeneous photocatalysis and biological treatment.

In the case of Leopard 5 EC neither of the methods was successful. The petroleum naphta solvent and/or the emulsifiers poisoned the $\mathrm{TiO}_{2}$ catalyst. The dollops formed settled and the surface of the catalyst particles was reduced greatly due to the adhesion effect of the organic material. The photocatalytic degradation reaction could not take place. A similar process was observed in the biological reactor. The mixture together with the biomass adhered to the surface of the sequenced batch reactor and sensors. In both cases the conditions made the treatment processes impossible. In order to be able to study the degradation of the
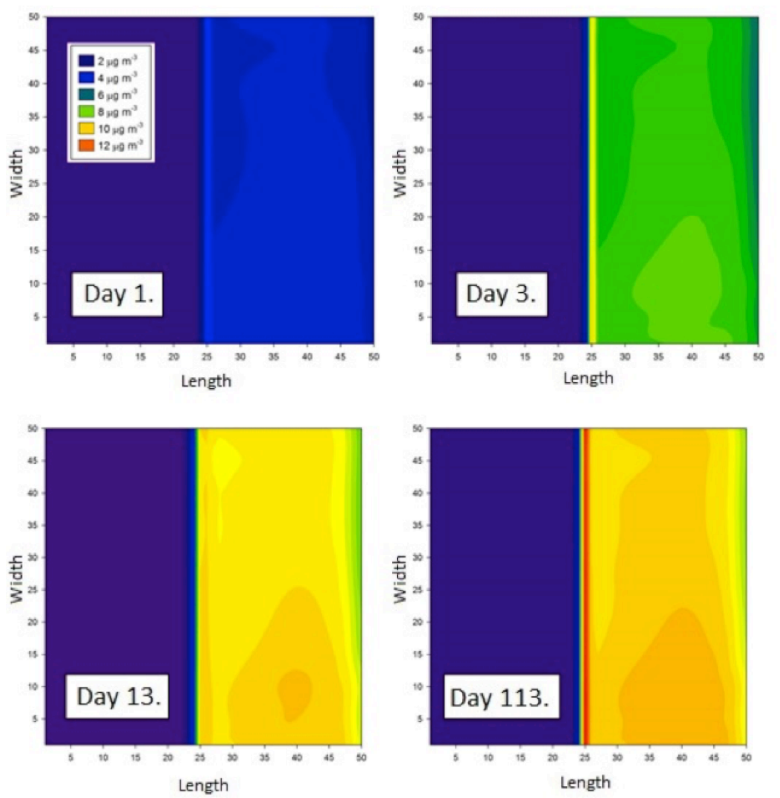

Figure 4. The concentration of acetamiprid in the second layer in the case of normal use (a unit equals $2 \mathrm{~m})$.

compound, pre-treatment, possibly the destabilisation of the emulsion is needed.

Mospilan 20 SG could be treated using heterogeneous photocatalysis both under laboratory conditions (with a UV lamp) and utilising solar radiation. However, it can be stated that the insecticide cannot be treated with municipal activated sludge under the applied conditions based on the results of sequenced batch reactor experiments.

According to the simulation results, neither of the pesticides poses a threat to drinking water resources in the case of normal use in compliance with the specifications provided by the manufacturer. Nonetheless, Mospilan 20 SG is likely to accumulate if used multiple times or for extended periods. Should there be an emergency the impact on the environment might multiply.

The results of the present study show that unlicensed use does not necessarily mean easily degradable substances. The biological method was unsuccessful in both cases, photocatalysis is not applicable for water-immiscible chemicals but in the case of hydrophilic organic materials, the treatment may be efficient.

\section{Acknowledgement}

The research was carried out with financial support from the project TÁMOP-4.1.1.C-12/1/KONV-20120015 .

\section{REFERENCES}

[1] The Stockholm Convention on Persistent Organic Pollutants (Stockholm Convention) 2014 cchm.pops.int 
[2] Solymosné Majzik, E.: Determination of concentration of pesticide active ingredients in groundwater and surface water samples applying various SPE methods, PhD thesis (University of Pannonia, Veszprém, Hungary) 2006 (in Hungarian)

[3] Khan, F.I.; Husain, T., Hejazi, R.: An overview and analysis of site remediation technologies, $J$. Environ. Mgmt., 2004 71, 95-122 10.1016/j.jenvman.2004.02.003

[4] Fujishima, A.; Honda, K.: Electrochemical photolysis of water at a semiconductor electrode, Nature, 1972 238, 37-38 10.1038/238037a0

[5] Fujishima, A.; Rao, T.N.; Tryk, D.A.: Titanium dioxide photocatalysis, J. Photochem. Photobiol. C: Rev., 2000 1, 1-21 10.1016/S1389-5567(00)00002-2

[6] Cazoir, D.; Fine, L.; Ferronato, C.; Chovelon, J.M.: Hydrocarbon removal from bilgewater by a combination of air-stripping and photocatalysis, $J$. Hazard. Mat., $2012 \quad$ 235-236, 159-168 10.1016/j.jhazmat.2012.07.037

[7] Irawaty, W.; Edi Soetaredjo, F.; Ayucitra, A.: Understanding the relationship between organic structure and mineralization rate of $\mathrm{TiO}_{2}$-mediated photocatalysis, Procedia Chem., 2014 9, 131-138 10.1016/j.proche.2014.05.016
[8] Esplugas, S.; Giménez, J.; Contreras, S.; Pascual, E.; Rodríguez, M.: Comparison of different advanced oxidation processes for phenol degradation, Water Res., 2002 36, 1034-1042 10.1016/S0043-1354(01)00301-3

[9] Malato Rodríguez, S.; Blanco Gálvez, J.; Maldonado Rubio, M.I.; Fernández Ibáñez, P.; Gernjak, W.; Oller Alberola, I.: Treatment of chlorinated solvents by $\mathrm{TiO}_{2}$ photocatalysis and photo-Fenton: influence of operating conditions in a solar pilot plant, Chemosphere, 2005 58, 391398 10.1016/j.chemosphere.2004.09.043

[10] Dombi, A., Ilisz, I.: Advanced oxidation processes in environmental chemistry, In Novel results of chemistry (Akadémiai Kiadó, Budapest, Hungary) 2000, Vol. 86 (in Hungarian)

[11] Jolánkai, M., Birkás, M.: Global Climate Change Impacts on Crop Production in Hungary, Agriculturae Conspectus Scientificus, 2007 72, 1720

[12] Gribovszki, Z.: Fundamentals of agricultural infrastructure 7, Drainage as a part of complex water management: Basics of hydrology and hydraulics (University of West Hungary, Sopron, Hungary) 2010 (in Hungarian) 


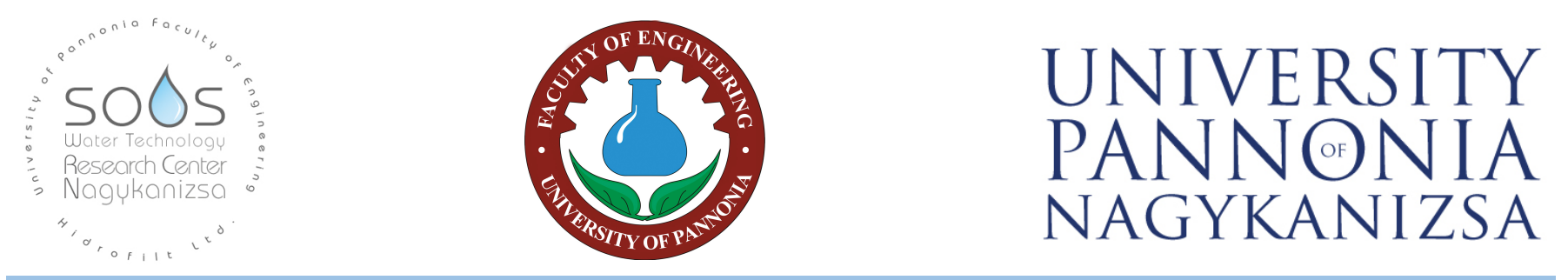

About water for water -

WATER AND WASTEWATER TREATMENT SYSTEM OPERATING ENGINEER

postgraduate specialist training course with the co-operation of one of Hungary's

oldest historical universities and a company of international reputation

\author{
"WATER IS ESSENTIAL FOR LIFE ON EARTH AS MUCH AS \\ GOOD QUALITY EDUCATION IS FOR PROFESSIONAL EXPERTS."
}

The University of Pannonia Faculty of Engineering and the Nagykanizsa Campus along with HIDROFILT Water and Wastewater Treatment Ltd. are offering a postgraduate course programme in water and wastewater treatment.

Hungary has long been recognised as a great water power with a historical background in the field of water treatment and purification. The University of Pannonia has a long tradition of academic excellence based on the training of engineering specialists for industry and the economy. The Faculty of Engineering and the Nagykanizsa Campus of the University of Pannonia are committed to forging partnerships with industry. Our aim is to create a generation of engineers that will take a lead in the development of innovative and sustainable technologies.

The Water and Wastewater Treatment System Operation Programme is designed for those engineering and non-engineering graduates who wish to pursue a career in water and wastewater treatment.

The Nagykanizsa Campus offers a wide spectrum of quality programmes that not only enhance students' professional development, but also familiarise them with the natural and historic values of Hungary. Mentors will assist students in organising their educational programmes and review their theses. Each student benefits from the opportunity of acquiring a broad range of transferable skills towards their future career within an outstanding academic environment.

Duration of the course programme: 2 semesters/4 months.

Theoretical training in water and wastewater treatment technologies is provided by the University of Pannonia, and Hidrofilt Ltd. Practical work and laboratory sessions will be carried out with the help of professional mentors from Hidrofilt Ltd. The Faculty of Engineering provides course materials and notes that are included in the package. Competencies to be acquired:

- Classification and adequate employment of the theoretical knowledge and practical methods acquired in the field; independent decision-making and development skills.

- Ability to analyse the qualitative and quantitative characteristics of water and wastewater; creating, implementing and assessing measurement plans.

- Optimal employment and management of state-of-the-art water and wastewater treatment technologies.

- Operating, planning and managing water supply and water and wastewater treatment technologies.

- Knowledge and employment of quality assurance and technical control.

- Analytical skills in technical, economical, and social relations in water and wastewater treatment.

- Evaluation of conceptions and programmes regarding water on national and international levels.

The qualification provides skills and abilities that can be employed profitably not only on a national but also on an international level. Graduates are able to design and implement investments related to water and wastewater treatment and maintain systems in operation.

We offer a practice-oriented training programme in addition to high-quality academic education. Those participating in the study programme gain state-of-the-art knowledge that fits the needs of the market and acquire the most advanced water purification technologies applied in the industry.

Information available from: info@sooswrc.hu 